\title{
SPHERICAL POTENTIALS OF COMPLEX ORDER IN WEIGHTED GENERALIZED HÖLDER SPACES WITH RADIAL OSCILLATING WEIGHTS
}

\author{
NATASHA SAMKO AND BORIS VAKULOV
}

\begin{abstract}
For the spherical potential and hypersingular operators, in general of complex order including the purely imaginary case, there are proved weighted Zygmund type estimates with radial type weights of the Zygmund-Bary-Stechkin class, which may oscillate between power functions. By means of those estimates there are proved boundedness theorems for these operators in weighted generalized Hölder spaces and it is shown that the potential type operator realizes a certain isomorphism within the frameworks of such spaces.
\end{abstract}

Mathematics subject classification (2000): 47B38, 47G10, 46E15, $26 \mathrm{~B} 35$.

Key words and phrases: Spherical convolution operators, spherical potentials, indices of almost monotonic functions, Boyd-type indices, continuity modulus, generalized Hölder spaces.

\section{REFERENCES}

[1] N. K. BARI AND S. B. STEChKIN, Best approximations and differential properties of two conjugate functions (in Russian), Proceedings of Moscow Math. Soc., 5 (1956) 483-522.

[2] A. I. GuSEINOV AND H. SH. MuKHTAROV, Introduction to the theory of nonlinear singular integral equations (in Russian), Moscow, Nauka, 1980., 416 pages.

[3] N. K. KARAPETIANTS AND N. G. SAMKO, Weighted theorems on fractional integrals in the generalized Hölder spaces $H_{0}^{\omega}(\rho)$ via the indices $m_{\omega}$ and $M_{\omega}$, Fract. Calc. Appl. Anal., 7(4) (2004) 437-458.

[4] N. K. KARAPETIANTS AND L. D. SHANKISHVILI, Fractional integro-differentiation of the complex order in generalized Holder spaces $H_{0}^{\omega}([0,1], \rho)$, Integral Transforms Spec. Funct., 13 (3) (2002) 199-209.

[5] N. G. SAMKO, On boundedness of singular operator in weighted generalized Hölder spaces $H_{0}^{\omega}(\Gamma, \rho)$ in terms of upper and lower indices of these spaces (in Russian), Deponierted in VINITI, Moscow, 1991., No. 349-B91, 28p.

[6] N. G. SAMKO, Singular integral operators in weighted spaces with generalized Hölder condition, Proc. A. Razmadze Math. Inst, 120 (1999) 107-134.

[7] N. G. SAMKO, On non-equilibrated almost monotonic functions of the Zygmund-Bary-Stechkin class, Real Anal. Exch., 30 (2) (2005) 727.

[8] S. G. SAMKo, Hypersingular Integrals and their Applications, London-New-York: Taylor \& Francis, Series "Analytical Methods and Special Functions", vol. 5, 2002., $358+$ xvii pages.

[9] S. G. SAMKO AND Z. MussalaEVA, Fractional type operators in weighted generalized Hölder spaces, Proc. Georgian Acad. Sci., Mathem., 1 (5) (2005) 601-626.

[10] B. G. VAKUlov, Potential type operator on a sphere in generalized Hölder classes, Izv. Vuzov. Matematika, 11 (1986) 66-69.

[11] B. G. VAKULOV, Spherical operators of potential type in generalized weighted Hölder space on a sphere, Izv. Vyssh. Uchebn. Zaved. Sev.-Kavk. Reg. Estestv. Nauki, (4):5-10, 127, 1999.

[12] B. G. VAKULOV, N. K. KARAPETIANTS, AND L. D. ShanKISHVILI, Spherical hypersingular operators of imaginary order and their multipliers, Fract. Calc. Appl. Anal., 4(1) (2001) 101-112.

[13] B. G. VAKUlov, N. K. KARAPETIANTS, AND L. D. ShanKISHVILI, Spherical potentials of complex order in generalized Hölder spaces, Izv. Nats. Akad. Nauk Armenii Mat., 36 (2) (2001) 54-78. 
[14] B. G. VAKUlov, N. K. KARAPETIANTS, AND L. D. ShanKiSHVILI, Spherical potentials of complex order in generalized weighted Hölder spaces, Dokl. Akad. Nauk, 382 (3) (2002) 301-304.

(c) AEVI, Zagreb

Paper No. 01-19 